\title{
Therapy Algorithms for the Diagnosis and Treatment of Patients with Early and Advanced Breast Cancer
}

\author{
Andreas Schneeweiss $^{a}$ Ingo Bauerfeind ${ }^{b}$ Tanja Fehm ${ }^{c}$ Wolfgang Janni ${ }^{d}$ \\ Christoph Thomssen $^{\mathrm{e}}$ Isabell Witzel ${ }^{f}$ Achim Wöckelg $^{g}$ Volkmar Müller $^{f}$ \\ on behalf of the Commission Breast of the Working Group Gynecologic \\ Oncology (AGO) \\ a National Center for Tumor Diseases, University Hospital and German Cancer Research Center, Heidelberg, \\ Germany; ${ }^{b}$ Clinic for Gynecology and Obstetrics, Landshut, Germany; ${ }^{\mathrm{c} D e p a r t m e n t}$ of Gynecology and Obstetrics, \\ University Hospital, Düsseldorf, Germany; ${ }^{\mathrm{d}}$ Department of Gynecology and Obstetrics, University Hospital, \\ Ulm, Germany; ${ }^{e}$ Department of Gynecology and Obstetrics, University Hospital, Halle, Germany; ${ }^{f}$ Department of \\ Gynecology, University Medical Center Hamburg-Eppendorf, Hamburg, Germany; ${ }^{9}$ Department of Gynecology \\ and Obstetrics, University Hospital, Würzburg, Germany
}

\section{Keywords}

Breast cancer guidelines - Therapy algorithms .

Evidence-based treatment

\section{Abstract}

Background: In order to offer optimal treatment approaches based on available evidence, the Commission Breast of the Working Group Gynecologic Oncology (AGO) of the German Cancer Society developed therapy algorithms for eight complex treatment situations in primary and advanced breast cancer. Summary: Therapy algorithms for the following complex treatment situations are outlined in this paper: (neo)adjuvant therapy of human epidermal growth factor receptor 2 (HER2)-positive breast cancer; axillary surgery and neoadjuvant chemotherapy; adjuvant endocrine therapy in premenopausal patients; adjuvant endocrine therapy in postmenopausal patients; hormone receptor (HR)-positive/ HER2-negative metastatic breast cancer: strategies; HR-positive/HER2-negative metastatic breast cancer: endocrinebased first-line treatment; HER2-positive metastatic breast cancer: first to third-line; metastatic triple-negative breast cancer. Key Messages: The therapy options shown in these algorithms are based on the current AGO recommendations
\end{abstract}

karger@karger.com www.karger.com/brc

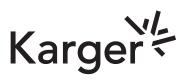

BOPEN ACCESS
(C) 2020 The Author(s)

Published by S. Karger AG, Basel

This is an Open Access article licensed under the Creative Commons Attribution-NonCommercial-4.0 International License (CC BY-NC) (http://www.karger.com/Services/OpenAccessLicense), applicable to the online version of the article only. Usage and distribution for commercial purposes requires written permission. updated in January 2020 but cannot represent all evidencebased treatment options. Prior therapies, performance status, comorbidities, patient preference, etc. must be taken into account for the actual treatment choice. Therefore, in individual cases, other evidence-based treatment options not listed here may also be appropriate and justified.

(c) 2020 The Author(s)
Published by S. Karger AG, Basel

\section{Introduction}

On the basis of the current Working Group Gynecologic Oncology (AGO) recommendations for the diagnosis and treatment of patients with early and advanced breast cancer updated in January 2020, a task force consisting of eight members of the Commission Breast of the AGO developed drafts for eight therapy algorithms of complex treatment situations in patients with early and advanced breast cancer. Those drafts were then discussed and finally approved by all active members of the Commission Breast of the AGO in virtual meetings. The members of the Commission Breast are completely aware of many other complex treatment situations for which such therapy algorithms are needed. Depending on the useful- 


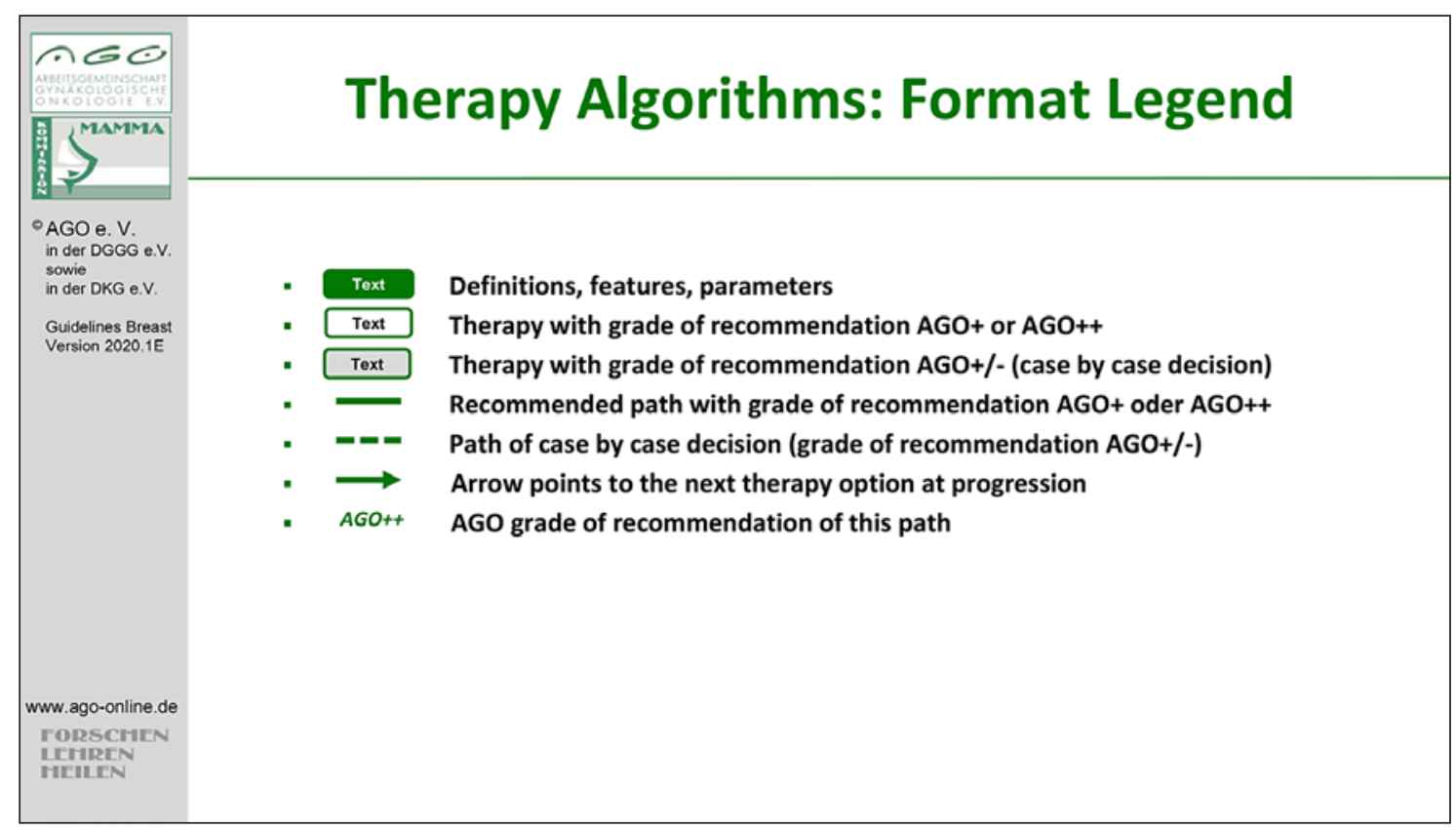

Fig. 1. Format legend.

Table 1. AGO grades of recommendation

\begin{tabular}{ll}
\hline $\begin{array}{l}\text { AGO grade of } \\
\text { recommendation }\end{array}$ & Definition \\
\hline++ & $\begin{array}{l}\text { this investigation or therapeutic intervention is highly beneficial for patients, can be recommended without } \\
\text { restriction, and should be performed }\end{array}$ \\
\hline+ & this investigation or therapeutic intervention is of limited benefit for patients and can be performed \\
\hline$+/-$ & this investigation or therapeutic intervention has not shown benefit for patients and may be performed only in \\
& individual cases; according to current knowledge a general recommendation cannot be given \\
\hline- & this investigation or therapeutic intervention can be of disadvantage for patients and might not be performed \\
\hline-- & $\begin{array}{l}\text { this investigation or therapeutic intervention is of clear disadvantage for patients and should be avoided or } \\
\text { omitted in any case }\end{array}$ \\
\hline
\end{tabular}

AGO, Working Group Gynecologic Oncology.

ness and usage of the algorithms outlined in this paper, the development of further algorithms is planned. The definitions of AGO grades of recommendation are listed in Table 1. Figure 1 shows the formats used in the algorithms.

\section{(Neo)Adjuvant Therapy of HER2-Positive Breast Cancer (Fig. 2)}

Human epidermal growth factor receptor 2 (HER2)positive breast cancer clinical stage $\mathrm{T} 1 \mathrm{~N} 0$, confirmed following surgery as $\mathrm{pT} 1 \mathrm{pN} 0$, should receive a de-esca- lated adjuvant therapy with 12 doses of paclitaxel weekly plus trastuzumab (Tz) for 1 year (AGO grade of recommendation $+[\mathrm{AGO}+])[1]$. If pathological $\mathrm{T}$ or $\mathrm{N}$ stage are higher, patients should receive a full-term adjuvant $\mathrm{Tz}$-based regimen (if pN0, AGO++) $[2,3]$ or a pertuzumab $(\mathrm{Pz})$ plus Tz-based regimen $(\mathrm{AGO}+)[4,5]$. In case of hormone receptor (HR)-positive, HER2-positive breast cancer, extended adjuvant treatment with neratinib might be discussed only following a Tz-containing Pz-free adjuvant therapy (AGO+) [6]. In all other cases, if systemic chemotherapy is indicated, patients with HER2-positive breast cancer should receive a fullterm Pz plus Tz-based neoadjuvant systemic therapy for 


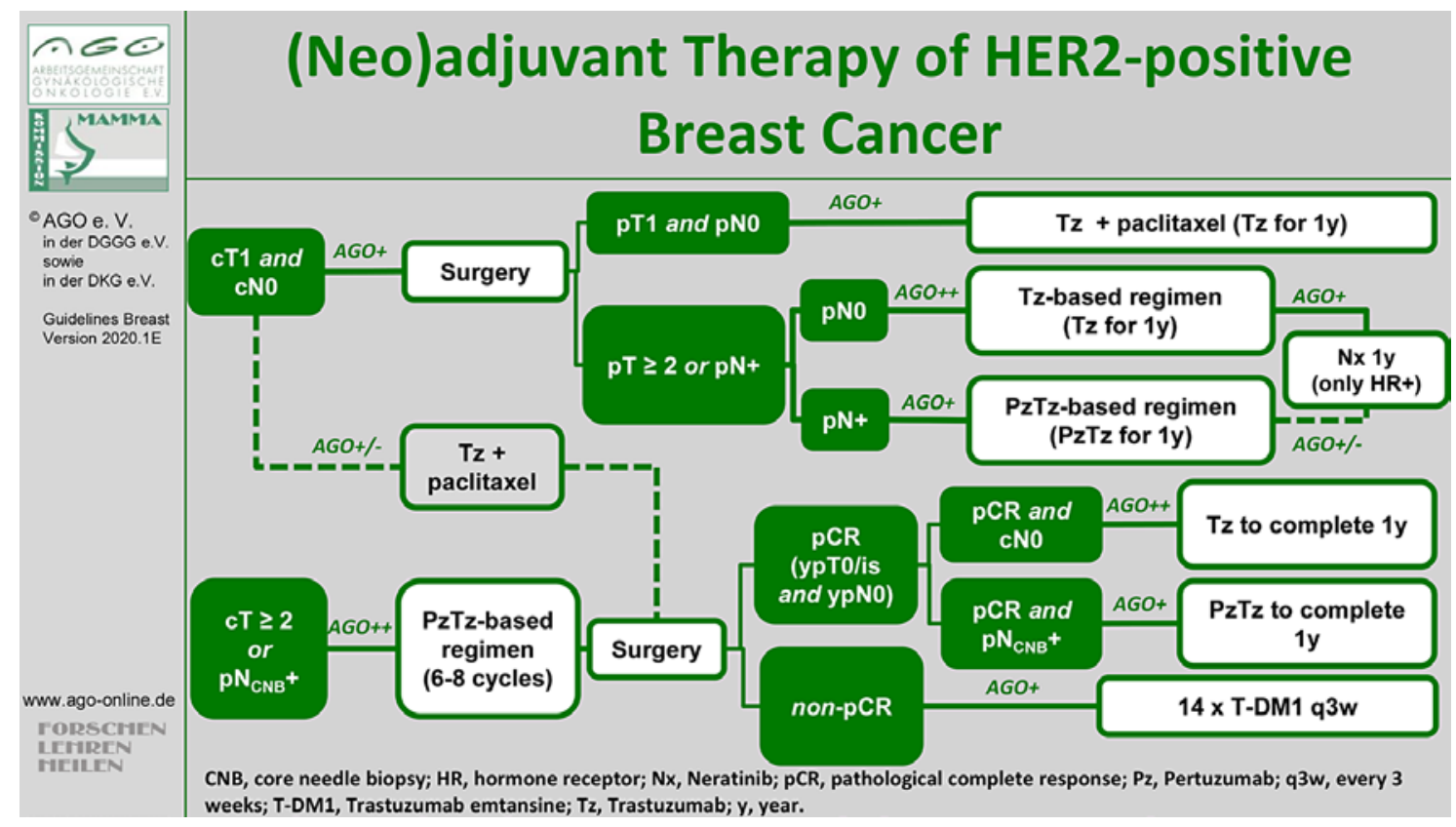

Fig. 2. (Neo)adjuvant therapy of HER2-positive breast cancer.

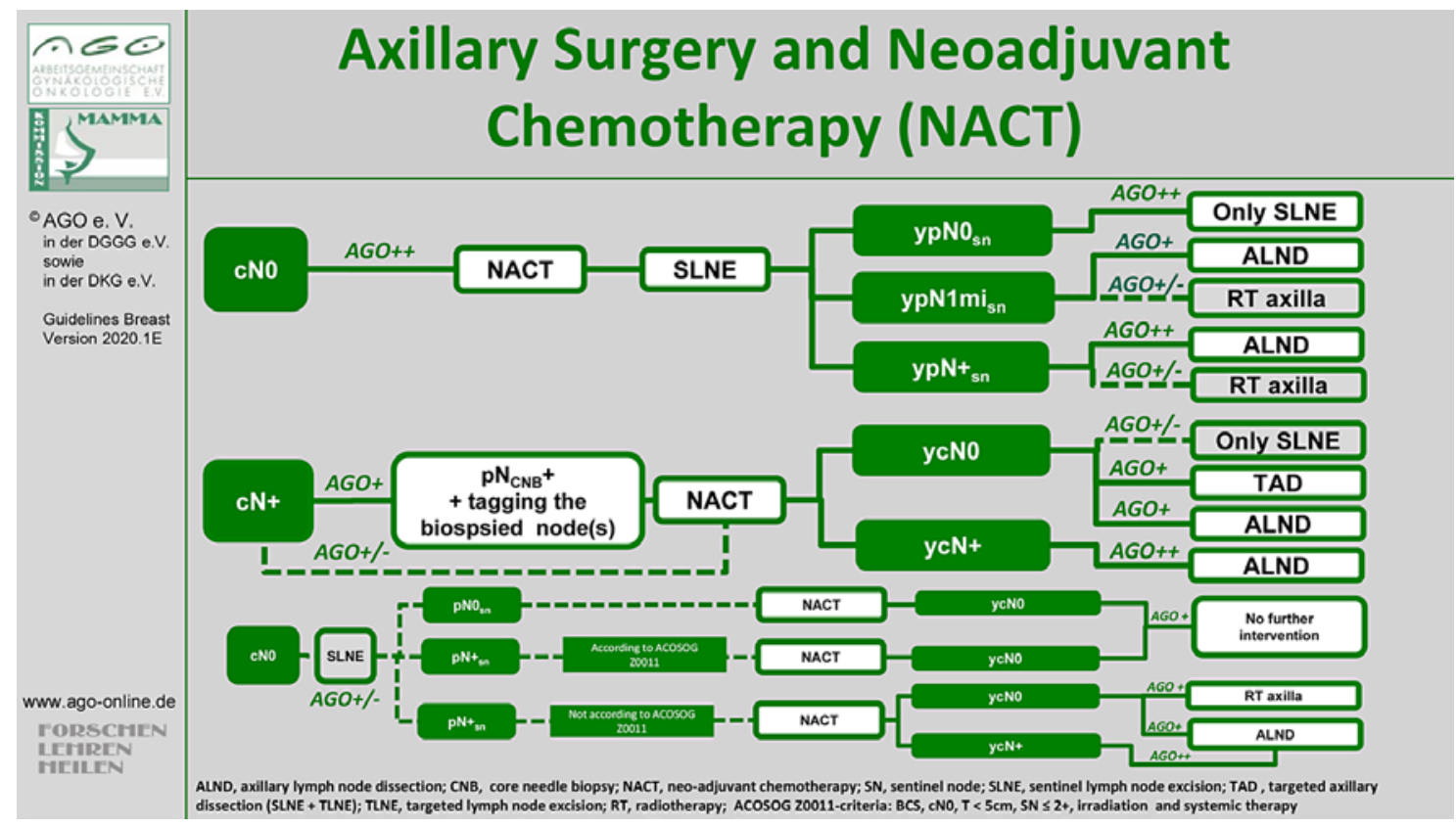

Fig. 3. Axillary surgery and neoadjuvant chemotherapy.

6-8 cycles $(\mathrm{AGO}++)[7,8]$. In case of pathological complete response (pCR), defined as ypT0/is and ypN0, continuation of the anti-HER2 antibody therapy is recommended up to the completion of 1 year. In patients with pCR and negative lymph nodes before and after neoadjuvant systemic therapy, Tz monotherapy might be sufficient $(\mathrm{AGO}++)$ [9]. In patients with lymph node involvement prior to neoadjuvant systemic therapy, dual
HER2 blockade with Tz plus $\mathrm{Pz}$ is recommended despite pCR (AGO+). Patients who have residual invasive disease in the breast or lymph nodes following optimal neoadjuvant systemic therapy including a taxane and at least $\mathrm{Tz}$ for 9 weeks should receive 14 cycles of trastuzumab emtansine (T-DM1) as adjuvant treatment $(\mathrm{AGO}+)[10]$. 


\section{Axillary Surgery and Neoadjuvant Chemotherapy (Fig. 3)}

Sentinel lymph node biopsy (SLNB) should be performed after neoadjuvant chemotherapy (NACT) (AGO+) [11-16]. In case of clinical and sonographic negative axillary lymph nodes before and after NACT, SLNB is the axillary staging method of choice. If no sentinel lymph node (SLN) shows tumor involvement, further axillary interventions are not indicated (AGO++). In case of positive SLN after NACT, axillary lymph node dissection is strongly recommended (AGO++). Also in case of histologically proven micrometastatic SLN involvement after NACT $\left(y p N 1 \mathrm{mic}_{S \mathrm{~S}}\right)$, axillary lymph node dissection should be performed (AGO+) because low-volume SLN disease after NACT is not an indicator of a low risk of additional positive axillary nodes [17]. Prospective survival data are lacking [18]. Clinically lymph node involvement before NACT should be verified by core needle biopsy. It is recommended to tag those lymph nodes (AGO+). If lymph node status is converted to clinically node-negative after NACT, targeted axillary dissection is preferred because false-negative rates are reported to be $<10 \%[16,17]$. A sole SLNB in these situations causes false-negative rates between 12 and $14 \%$ and does not allow adequate stratification of post-neoadjuvant treatment $[11-15,19]$. SLNB before NACT is possible in clinically lymph node-negative patients but not recommended (AGO+/-). The SENTINA trial reported $30 \%$ of tumor-involved lymph nodes in clinically lymph node-negative patients before NACT. In case of SLN involvement before NACT, evidence-based subsequent procedures have not been evaluated yet. Therefore, SLNB should be performed after NACT.

\section{Adjuvant Endocrine Therapy in Breast Cancer Patients (Fig. 4a, b)}

Patients with estrogen receptor-positive breast cancer should receive adjuvant endocrine treatment. In pre- or perimenopausal patients, standard treatment includes tamoxifen for at least 5 years $(\mathrm{AGO}++)$ [20]. In patients with higher risk of recurrence (e.g., $\mathrm{pN}+$ ), extended adjuvant treatment with either tamoxifen for further 5 years, if still premenopausal (AGO++), or aromatase inhibitor (AI) for 2-5 years, if postmenopausal after 5 years of endocrine treatment (AGO+), should be recommended [21, 22]. Adding ovarian suppression with gonadotropin-releasing hormone agonists ( $\mathrm{GnRHa}$ ) might be an option for patients who received chemotherapy and regain ovarian function within 2 years after the end of chemotherapy. Ovarian function is defined by menstruation, or estradiol or follicle stimulating hormone levels in the pre- or perimenopausal range. In patients 35 years or older who re- gain ovarian function, GnRHa should be added to tamoxifen for 5 years (AGO+) [23]. In patients under 35 years of age, tamoxifen plus GnRHa $(\mathrm{AGO}++)$ or AI plus $\mathrm{GnRHa}(\mathrm{AGO}+)$ for 5 years are options [23, 24]. All patients who received chemotherapy and are premenopausal after 5 years should receive extended adjuvant treatment with tamoxifen for further 5 years (AGO+) [21].

In postmenopausal patients the standard treatment includes an AI. Only very old patients and patients with a very low risk of recurrence or with contraindications for AI can receive tamoxifen only for 5 years (AGO+) [20]. Extended adjuvant treatment with tamoxifen for further 5 years might be discussed [21]. In all other cases, patients should receive tamoxifen for 2-3 years followed by AI (for a total of 5 years) or AI for 2-3 years followed by tamoxifen (for a total of 5 years) or AI for 5 years (AGO++) [25]. In patients with invasive lobular histology, a nonsteroidal AI for 5 years might be discussed (AGO+) [25]. In patients with high risk of recurrence, extended adjuvant treatment with an AI for 2-5 years should be recommended (AGO+) [26]. The decision criteria for the definition of high risk of recurrence may include (neo)adjuvant chemotherapy (indicating high risk), positive lymph node status, T2/T3 tumors, and elevated risk of recurrence based on immunohistochemical criteria or based on multi-gene expression assays or high CTS5 score.

\section{HR-Positive/HER2-Negative Metastatic Breast Cancer: Strategies (Fig. 5a)}

Recent evidence has resulted in additional therapeutic options for the treatment of advanced or metastatic HRpositive and HER2-negative breast cancer. In order to reach the therapeutic goal of maintaining a quality of life as high as possible, today the first-line standard of care therapy is endocrine-based combination with a cyclindependent kinase 4/6 (CDK4/6) inhibitor (abemaciclib, palbociclib, ribociclib) plus endocrine therapy (AI or fulvestrant) $(\mathrm{AGO}++)[27,28]$. Only if a very rapid response is required due to severe symptoms or imminent organ failure, cytostatic drugs $(\mathrm{AGO}++)$, if necessary combined with bevacizumab $(\mathrm{AGO}+)$, should be used as first-line therapy [29-32]. Second-line therapy options depend on the extent of progression, the need for response, and the patient's preference. In case of a BRCA1/2 germline mutation, therapy with poly(ADP-ribose)-polymerase (PARP) inhibitors can be offered as a valuable treatment option (AGO+) [33-39]. In addition, further single-agent or combination therapies are available. Besides the combination with everolimus, alpelisib will also be a future therapeutic option in case of PIK3CA mutation (AGO+) $[40,41]$. In case of endocrine resistance, cytotoxic drugs should be offered as further therapy (AGO+) [42]. 


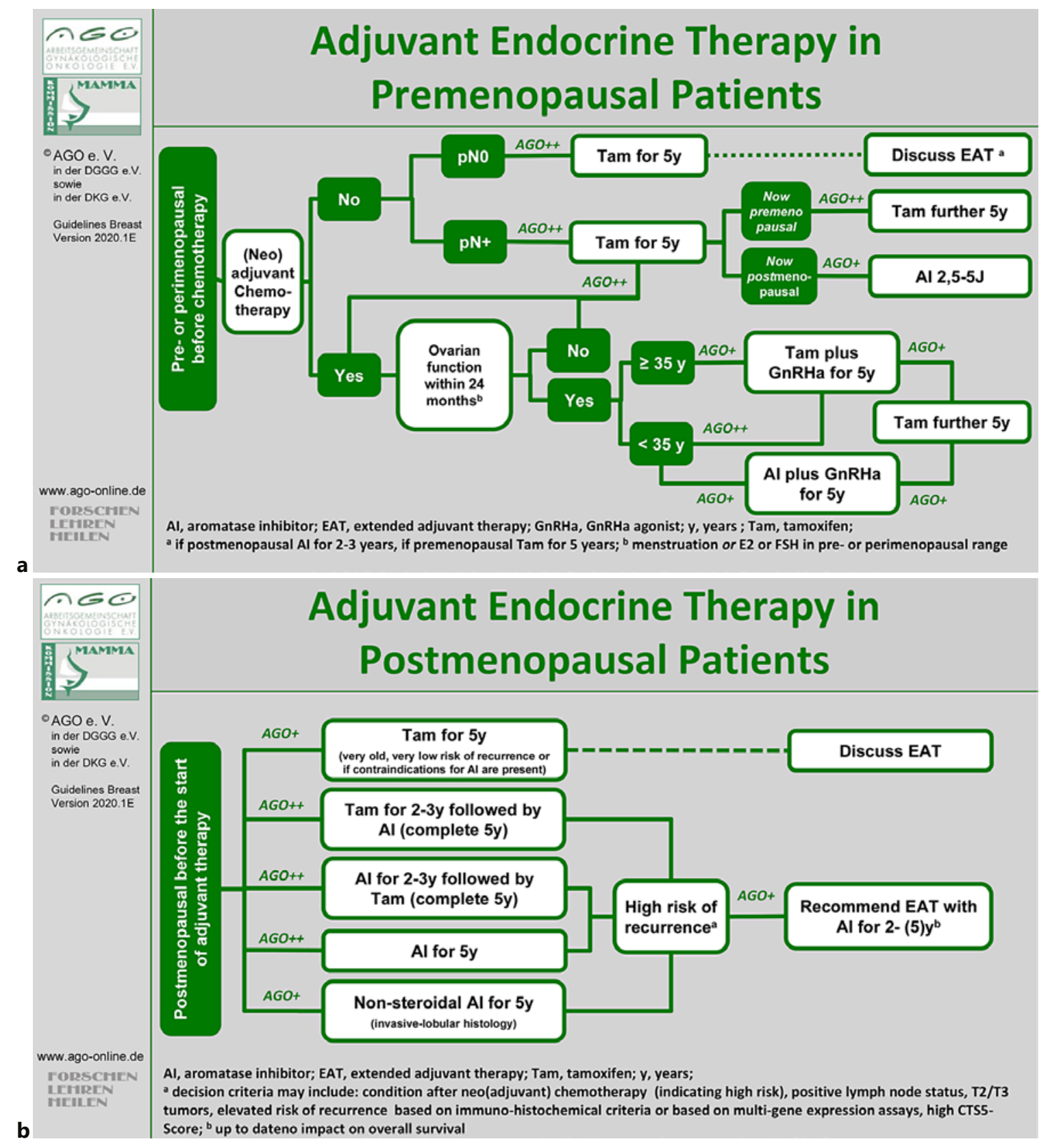

Fig. 4. Adjuvant endocrine therapy. a Premenopausal patients. b Postmenopausal patients.

\section{HR-Positive/HER2-Negative Metastatic Breast Cancer: Endocrine-Based First-Line Therapy (Fig. 5b)}

Data from the PALOMA, MONALEESA, and MONARCH studies showed significant and clinically relevant improvements of progression-free survival in pre-, peri-, and postmenopausal patients if CDK4/6 inhibitors have been used $(\mathrm{AGO}++)$ [43-59]. Currently, mature data regarding overall survival are only available for individual CDK4/6 inhibitors in defined situations. If CDK4/6 inhibitors are not administered, the initial approach in pre- menopausal patients is to suppress ovarian function (e.g., with $\mathrm{GnRHa}$ ) combined with tamoxifen $(\mathrm{AGO}++)[60$, 61]. In case of tumor progression on tamoxifen or if tamoxifen is contraindicated, a third-generation AI plus GnRHa can be administered (AGO+). In addition, fulvestrant plus GnRHa can be considered as a further option $(\mathrm{AGO}+)$ [62-65]. Depending on the previous adjuvant therapy, in postmenopausal patients AI and tamoxifen can be administered (AGO+) [66-72]. In particular after previous treatment with an $\mathrm{AI}$, treatment with fulvestrant should be considered (AGO+) [73-75]. 


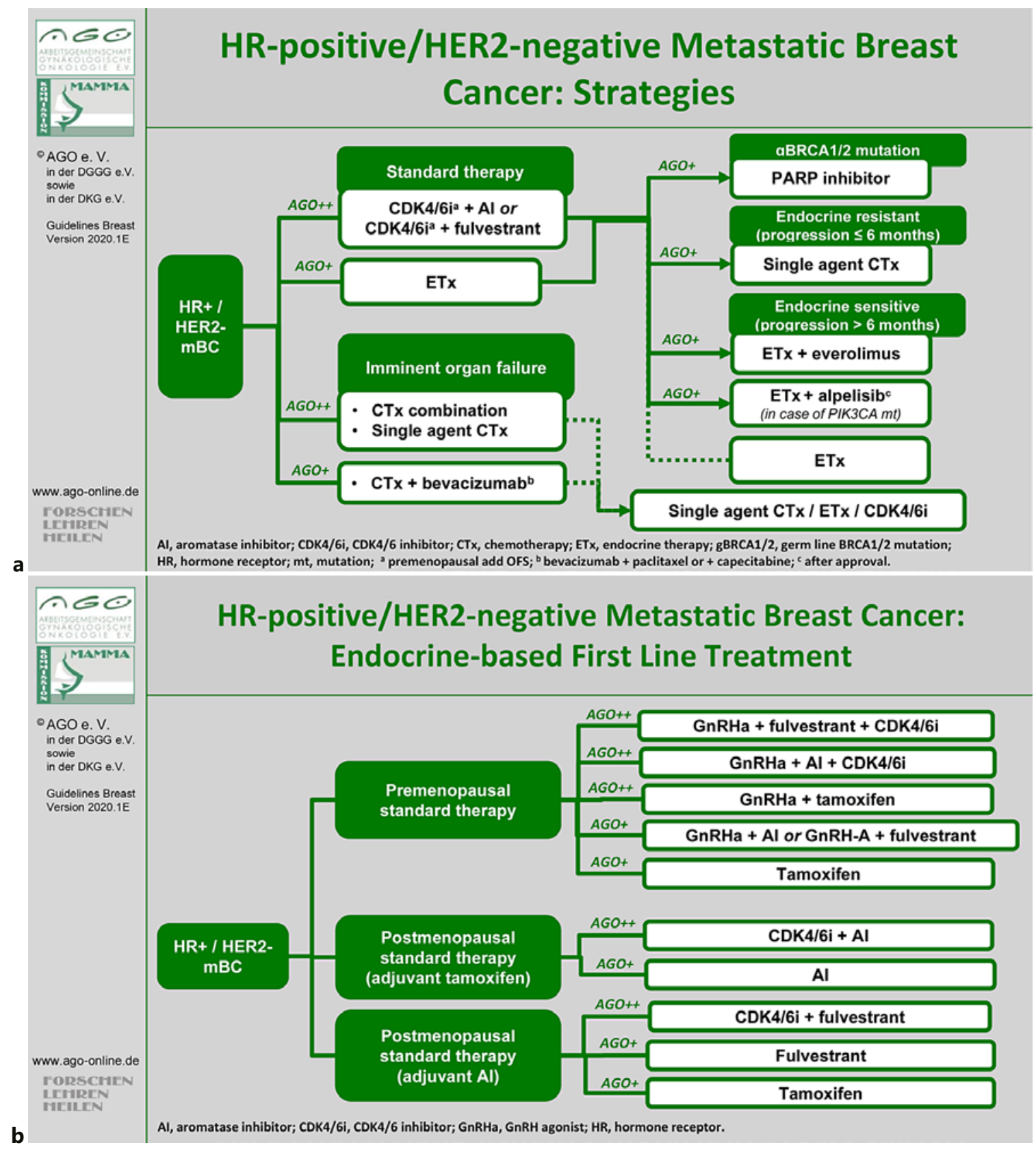

Fig. 5. HR-positive/HER2-negative metastatic breast cancer. a Strategies. b Endocrine-based first-line therapy.

\section{HER2-Positive Metastatic Breast Cancer: First to Third Line (Fig. 6)}

In the first-line setting, patients with HER2-positive metastatic breast cancer (treatment-free interval $>6$ months or previously untreated with anti-HER 2 targeted therapy) should be treated with a taxane and dual blockade of the HER2 receptor by $\mathrm{Tz}$ and $\mathrm{Pz}(\mathrm{AGO}++)$ [76]. If patients are HR-positive, a switch to endocrine treatment and dual blockade as maintenance therapy may be considered after successful induction chemotherapy, although this strategy has not been evaluated in random- ized clinical trials. In case of progressive disease, T-DM1 is an established second-line treatment $(\mathrm{AGO}++)[77$, 78]. For third or higher lines of treatment, no standard regimens are defined. Therefore, patients should be encouraged to participate in clinical trials investigating new experimental anti-HER2 drugs (AGO+). Otherwise, capecitabine plus lapatinib $[79,80]$ chemotherapy plus $\mathrm{Tz}$ [81], Tz plus $\mathrm{Pz}$ [82], or lapatinib plus $\mathrm{Tz}[83,84]$ may be therapeutic options to be discussed with the patient $(\mathrm{AGO}+)$. If patients have previously been treated with HER2 targeted therapy including $\mathrm{Tz}$ with or without $\mathrm{Pz}$ in the (neo)adjuvant setting and the treatment-free inter- 


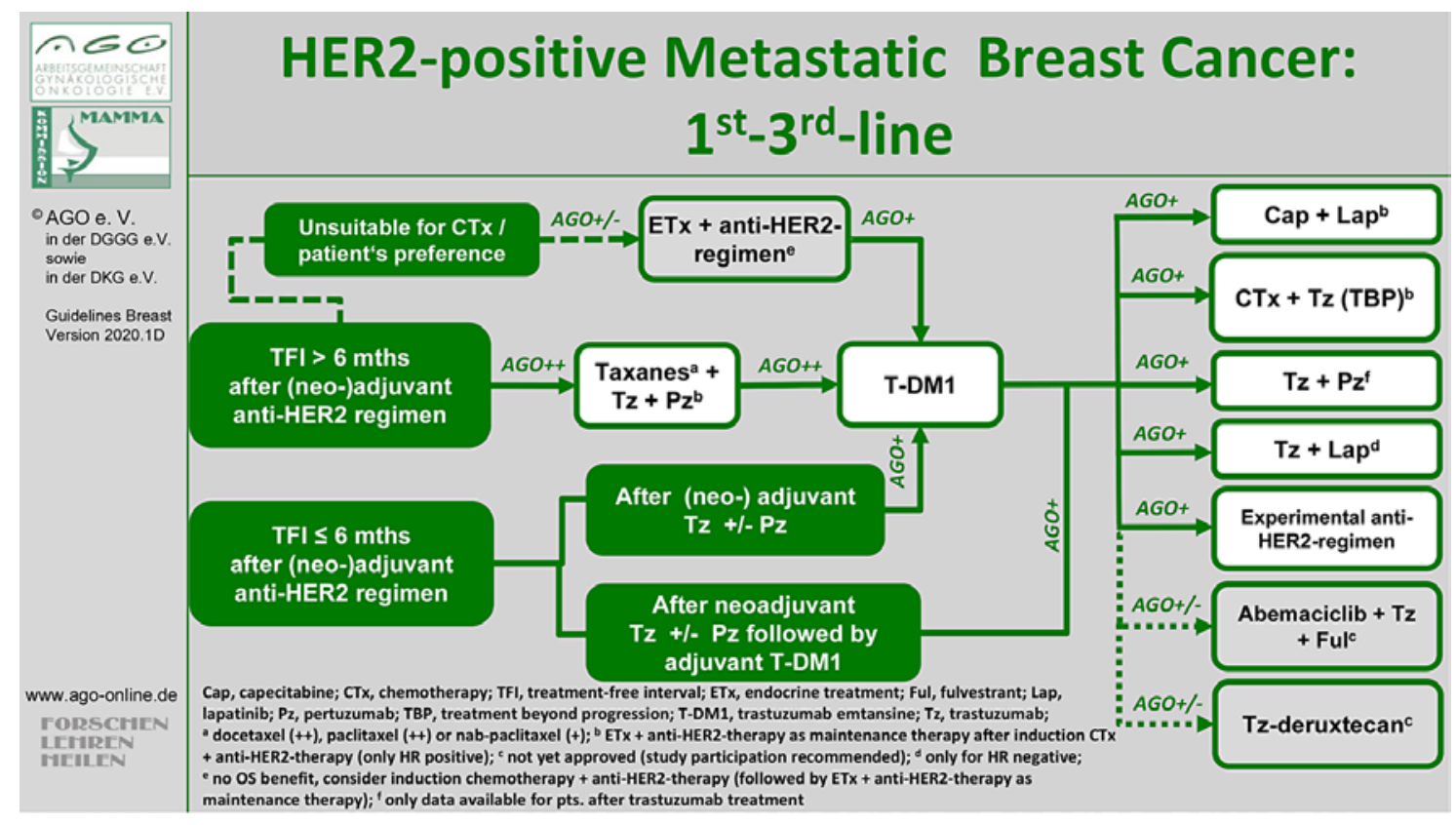

Fig. 6. HER2-positive metastatic breast cancer: first to third line.

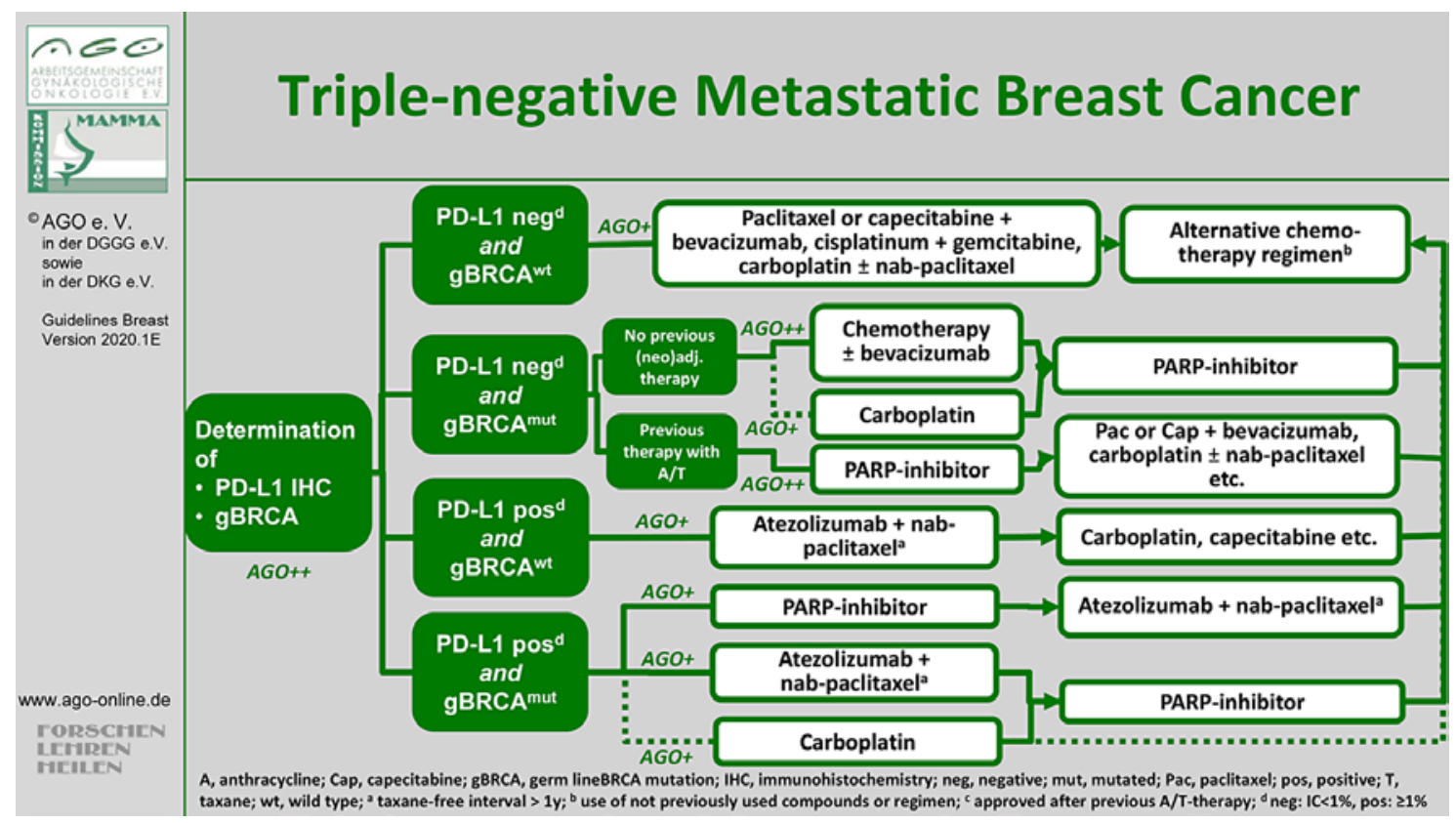

Fig. 7. Metastatic triple-negative breast cancer.

val is $<6$ months, T-DM1 as a first-line treatment should be considered (AGO+) followed by third-line options in case of disease progression. No established regimens are available for those metastatic patients who have received T-DM1 in the adjuvant setting after neoadjuvant Tz plus $\mathrm{Pz}$ and no pCR. Therefore, third-line options may be offered to these heavily HER2-pretreated patients. For triple-positive patients who are unsuitable for chemothera- py or prefer chemotherapy-free options, endocrine treatment in combination with HER 2 targeted therapy should be considered. However, no survival benefit has been demonstrated so far for these combinations compared to taxane and Tz plus Pz. Therefore, induction chemotherapy followed by endocrine treatment and dual blockade is still the preferred option in triple-positive patients who are suitable for chemotherapy (AGO++). 


\section{Metastatic Triple-Negative Breast Cancer (Fig. 7)}

In triple-negative breast cancer, metastatic recurrence occurs more often than in other breast cancer subtypes, and estrogen receptor- and HER2-directed treatment options are lacking. For adequate treatment, histopathology including analysis of programmed death ligand 1 (PDL1) expression and testing for germline BRCA mutations is required [42]. In $>50 \%$ of cases, single-agent or combination chemotherapy are the only treatment options. Based on performance status and need of remission, for first-line treatment of patients with metastatic triple-negative breast cancer (mTNBC), paclitaxel or capecitabine single-agent or combined with bevacizumab, gemcitabine plus cisplatin, or nab-paclitaxel plus carboplatin are recommended (AGO+) [85-90]. With further progression, any non-cross-resistant second-line chemotherapy can be delivered. Though most mTNBCs are of no special type, diagnosis of metaplastic carcinoma is associated with resistance against chemotherapy and the individual options have to be discussed [91]. If patients with a germline BRCA1/2 mutation (in the neoadjuvant setting approximately $15 \%$ of all cases with triple-negative breast cancer) [92] and no PD-L1 expression have been exposed to prior anthracyclines and taxanes, the treatment of choice is PARP inhibition with olaparib or talazoparib $(\mathrm{AGO}++)[34,36]$. In a stratified analysis, an overall survival advantage was demonstrated if olaparib was given as first-line therapy [34]. When patients get refractory to PARP inhibition, standard chemotherapy as listed above is indicated. In patients with germline BRCA mutation but no prior treatment with anthracyclines and taxanes (e.g., stage IV breast cancer), standard first-line chemotherapy is indicated $(\mathrm{AGO}++)$. Some data showed particular efficacy of single-agent carboplatin in patients with germline BRCA mutation (AGO+) [93]. After progressing on first-line chemotherapy, second-line PARP inhibition can be considered. In patients (10-35\%) with wild-type germline BRCA status and PD-L1-positive mTNBC (positive immune cells covering $\geq 1 \%$ of tumor area), first-line therapy with the immune checkpoint inhibitor atezolizumab in combination with nab-paclitaxel is indicated $(\mathrm{AGO}+)$. Of note, although the European Medicine Agency approved atezolizumab without restrictions, the pivotal trial has only included patients who have had no prior chemotherapy or at least a 12-month disease-free interval from the initial (neo)adjuvant therapy $[94,95]$. Less efficacy with disease-free interval $<12$ months has been shown for the PD-1 inhibitor pembrolizumab. In patients with germline BRCA mutation and PD-L1 tumor expression (maximum 6\%), both options (olaparib/talazoparib or atezolizumab plus nab-paclitaxel) can be discussed (AGO+) $[34,94,95]$. A crossover should always be considered in case of disease progres- sion. For patients with germline BRCA mutation, singleagent carboplatin may also be an option (AGO+) [44]. Finally, in case of progression on targeted therapy, all patients should be subjected to standard chemotherapy as listed above. Experimental approaches including molecular oncology should be considered.

\section{Conflict of Interest Statement}

A. Schneeweiss reports grants from Celgene, Roche, and AbbVie, personal fees from Roche, AstraZeneca, Celgene, Pfizer, Novartis, MSD, Tesaro, and Lilly, and travel grants from Roche and Celgene. I. Bauerfeind reports honoraria from Novartis, Celgene, Pfizer, Roche, GSK, and Lilly. T. Fehm reports honoraria from Daiichi Sankyo, Novartis, Roche, Lilly, MSD, HelloHealthcare, Amgen, AstraZeneca, Pfizer, and Olympus. W. Janni reports grants and personal fees from Amgen, AstraZeneca, Daiichi Sankyo, Lilly, MSD, MSB, Novartis, Pfizer, and Roche. C. Thomssen reports honoraria from Amgen, AstraZeneca, Celgene, Daiichi Sankyo, Eisai, Lilly, MSD, Mylan, Nanostring, Novartis, Pfizer, Pierre Fabre, Puma, Roche, and Vifor. I. Witzel reports honoraria from Amgen, Celgene, Daiichi Sankyo, Lilly, MSD, Novartis, Pfizer, Roche, and TEVA. A. Wöckel reports personal fees from Amgen, Novartis, Eisai, Celgene, Pfizer, Tesaro, TEVA, Hexal Lilly, Roche, AstraZeneca, Sirtex, MSD, and Genomic Health. V. Müller reports institutional research support from Novartis, Roche, Seattle Genetics, and Genentech, honoraria from Amgen, AstraZeneca, Daiichi Sankyo, Eisai, Pfizer, MSD, Novartis, Roche, Teva, Seattle Genetics, Genomic Health, Hexal, Pierre Fabre, Amgen, ClinSol, MSD, Lilly, Tesaro, and Nektar, and travel grants from Roche, Pfizer, and Daiichi Sankyo.

\section{Funding Sources}

No funding was received for the preparation of this review.

\section{Author Contributions}

All authors substantially contributed to conception and design of the review, to acquisition, analysis, and interpretation of the underlying database, to drafting and critical revising of the intellectual content, and to final approval of the version to be published. All authors agree to be accountable for all aspects of the review in ensuring that questions related to the accuracy or integrity of any part of the review are appropriately investigated and resolved.

\section{References}

1 Tolaney SM, Guo H, Pernas S, Barry WT, Dillon DA, Ritterhouse L, et al. Seven-Year Follow-Up Analysis of Adjuvant Paclitaxel and Trastuzumab Trial for Node-Negative, $\mathrm{Hu}$ man Epidermal Growth Factor Receptor 2-Positive Breast Cancer. J Clin Oncol. 2019 Aug;37(22):1868-75.

2 Perez EA, Romond EH, Suman VJ, Jeong JH, Sledge G, Geyer CE Jr, et al. Trastuzumab plus adjuvant chemotherapy for human epidermal growth factor receptor 2-positive breast cancer: planned joint analysis of overall survival from NSABP B-31 and NCCTG N9831. J Clin Oncol. 2014 Nov;32(33):3744-52. 
3 Cameron D, Piccart-Gebhart MJ, Gelber RD, Procter M, Goldhirsch A, de Azambuja E, et al.; Herceptin Adjuvant (HERA) Trial Study Team. 11 years' follow-up of trastuzumab after adjuvant chemotherapy in HER2-positive early breast cancer: final analysis of the HERceptin Adjuvant (HERA) trial. Lancet. 2017 Mar;389(10075):1195-205.

4 von Minckwitz G, Procter M, de Azambuja E, Zardavas D, Benyunes M, Viale G, et al.; APHINITY Steering Committee and Investigators. Adjuvant Pertuzumab and Trastuzumab in Early HER2-Positive Breast Cancer. N Engl J Med. 2017 Jul;377(2):122-31.

5 Piccart M, Procter M, Fumagalli D, de Azambuja E, Clark E, Ewer MS, et al. Interim overall survival analysis of APHINITY (BIG 4-11): a randomized multicenter, double-blind, placebo-controlled trial comparing chemotherapy plus trastuzumab plus pertuzumab versus chemotherapy plus trastuzumab plus placebo as adjuvant therapy in patients with operable HER2-positive early breast cancer. San Antonio Breast Cancer Symposium 2019; abstract GS 01-04.

6 Martin M, Holmes FA, Ejlertsen B, Delaloge S, Moy B, Iwata H, et al.; ExteNET Study Group. Neratinib after trastuzumab-based adjuvant therapy in HER2-positive breast cancer (ExteNET): 5-year analysis of a randomised, double-blind, placebo-controlled, phase 3 trial. Lancet Oncol. 2017 Dec;18(12): 1688-700.

7 Gianni L, Pienkowski T, Im YH, Roman L, Tseng LM, Liu MC, et al. Efficacy and safety of neoadjuvant pertuzumab and trastuzumab in women with locally advanced, inflammatory, or early HER2-positive breast cancer (NeoSphere): a randomised multicentre, open-label, phase 2 trial. Lancet Oncol. 2012 Jan;13(1):25-32.

8 Schneeweiss A, Chia S, Hickish T, Harvey V, Eniu A, Waldron-Lynch M, et al. Long-term efficacy analysis of the randomised, phase II TRYPHAENA cardiac safety study: evaluating pertuzumab and trastuzumab plus standard neoadjuvant anthracycline-containing and anthracycline-free chemotherapy regimens in patients with HER2-positive early breast cancer. Eur J Cancer. 2018 Jan;89:2735 .

9 Gianni L, Eiermann W, Semiglazov V, Lluch A, Tjulandin S, Zambetti M, et al. Neoadjuvant and adjuvant trastuzumab in patients with HER2-positive locally advanced breast cancer (NOAH): follow-up of a randomised controlled superiority trial with a parallel HER2-negative cohort. Lancet Oncol. 2014 May;15(6):640-7.

10 von Minckwitz G, Huang CS, Mano MS Loibl S, Mamounas EP, Untch M, et al.; KATHERINE Investigators. Trastuzumab Emtansine for Residual Invasive HER2-Positive Breast Cancer. N Engl J Med. 2019 Feb 380(7):617-28

11 Kuehn T, Bauerfeind I, Fehm T, Fleige B, Hausschild M, Helms G, et al. Sentinellymph-node biopsy in patients with breast cancer before and after neoadjuvant chemotherapy (SENTINA): a prospective, multicentre cohort study. Lancet Oncol. 2013 Jun; 14(7):609-18.
12 Boughey JC, Suman VJ, Mittendorf EA, Ahrendt GM, Wilke LG, Taback B, et al.; Alliance for Clinical Trials in Oncology. Sentinel lymph node surgery after neoadjuvant chemotherapy in patients with node-positive breast cancer: the ACOSOG Z1071 (Alliance) clinical trial. JAMA. 2013 Oct;310(14):145561.

13 Boughey JC, Suman VJ, Mittendorf EA, Ahrendt GM, Wilke LG, Taback B, et al.; Alliance for Clinical Trials in Oncology. Factors affecting sentinel lymph node identification rate after neoadjuvant chemotherapy for breast cancer patients enrolled in ACOSOG Z1071 (Alliance). Ann Surg. 2015 Mar;261(3): 547-52.

14 Boileau JF, Poirier B, Basik M, Holloway CM, Gaboury L, Sideris L, et al. Sentinel node biopsy after neoadjuvant chemotherapy in biopsy-proven node-positive breast cancer: the SN FNAC study. J Clin Oncol. 2015 Jan;33(3): 258-64.

15 Classe JM, Loaec C, Gimbergues P, Alran S, de Lara CT, Dupre PF, et al. Sentinel lymph node biopsy without axillary lymphadenectomy after neoadjuvant chemotherapy is accurate and safe for selected patients: the GANEA 2 study. Breast Cancer Res Treat. 2019 Jan;173(2):343-52.

16 Ditsch N, Rubio IT, Gasparri ML, de Boniface J, Kuehn T. Breast and axillary surgery in malignant breast disease: a review focused on literature of 2018 and 2019. Curr Opin Obstet Gynecol. 2020 Feb;32(1):91-9.

17 Moo TA, Edelweiss M, Hajiyeva S, Stempel M, Raiss M, Zabor EC, et al. Is Low-Volume Disease in the Sentinel Node After Neoadjuvant Chemotherapy an Indication for Axillary Dissection? Ann Surg Oncol. 2018 Jun; 25(6):1488-94.

18 Galimberti V, Ribeiro Fontana SK, Maisonneuve $\mathrm{P}$, Steccanella F, Vento AR, Intra $\mathrm{M}$, et al. Sentinel node biopsy after neoadjuvant treatment in breast cancer: five-year followup of patients with clinically node-negative or node-positive disease before treatment. Eur J Surg Oncol. 2016 Mar;42(3):361-8.

19 Tee SR, Devane LA, Evoy D, Rothwell J, Geraghty J, Prichard RS, et al. Meta-analysis of sentinel lymph node biopsy after neoadjuvant chemotherapy in patients with initial biopsyproven node-positive breast cancer. Br J Surg. 2018 Nov; 105(12):1541-52.

20 Davies C, Godwin J, Gray R, Clarke M, Cutter D, Darby S, et al.; Early Breast Cancer Trialists' Collaborative Group (EBCTCG). Relevance of breast cancer hormone receptors and other factors to the efficacy of adjuvant tamoxifen: patient-level meta-analysis of randomised trials. Lancet. 2011 Aug;378(9793): 771-84.

21 Davies C, Pan H, Godwin J, Gray R, Arriagada R, Raina V, et al.; Adjuvant Tamoxifen: Longer Against Shorter (ATLAS) Collaborative Group. Long-term effects of continuing adjuvant tamoxifen to 10 years versus stopping at 5 years after diagnosis of oestrogen receptor-positive breast cancer: ATLAS, a randomised trial. Lancet. 2013 Mar; 381(9869):805-16

22 Goss PE, Ingle JN, Martino S, Robert NJ, Muss HB, Piccart MJ, et al. Randomized trial of letrozole following tamoxifen as extended adjuvant therapy in receptor-positive breast cancer: updated findings from NCIC CTG MA.17. J Natl Cancer Inst. 2005 Sep;97(17): 1262-71.

23 Francis PA, Regan MM, Fleming GF, Láng I, Ciruelos E, Bellet M, et al.; SOFT Investigators; International Breast Cancer Study Group. Adjuvant ovarian suppression in premenopausal breast cancer. N Engl J Med. 2015 Jan;372(5):436-46.

24 Pagani O, Regan MM, Walley BA, Fleming GF, Colleoni M, Láng I, et al.; TEXT and SOFT Investigators; International Breast Cancer Study Group. Adjuvant exemestane with ovarian suppression in premenopausal breast cancer. N Engl J Med. 2014 Jul;371(2): 107-18.

25 Early Breast Cancer Trialists' Collaborative Group (EBCTCG). Aromatase inhibitors versus tamoxifen in early breast cancer: patientlevel meta-analysis of the randomised trials. Lancet. 2015 Oct;386(10001):1341-52.

26 Early Breast Cancer Trialists' Collaborative Group (EBCTCG). Extended aromatase inhibitor treatment following 5 or more years of endocrine therapy: a meta-analysis of 22,192 women in 11 randomised trials. SABCS 2018; GS3-03.

27 Petrelli F, Ghidini A, Pedersini R, Cabiddu M, Borgonovo K, Parati MC, et al. Comparative efficacy of palbociclib, ribociclib and abemaciclib for ER+ metastatic breast cancer: an adjusted indirect analysis of randomized controlled trials. Breast Cancer Res Treat. 2019 Apr;174(3):597-604.

28 Rossi V, Berchialla P, Giannarelli D, Nisticò C, Ferretti G, Gasparro S, et al. Should All Patients With HR-Positive HER2-Negative Metastatic Breast Cancer Receive CDK 4/6 Inhibitor As First-Line Based Therapy? A Network Meta-Analysis of Data from the PALOMA 2, MONALEESA 2, MONALEESA 7, MONARCH 3, FALCON, SWOG and FACT Trials. Cancers (Basel). 2019 Oct; 11(11): 1661.

29 Qi WX, Tang LN, He AN, Shen Z, Yao Y. Comparison between doublet agents versus single agent in metastatic breast cancer patients previously treated with an anthracycline and a taxane: a meta-analysis of four phase III trials. Breast. 2013 Jun;22(3):314-9.

30 Belfiglio M, Fanizza C, Tinari N, Ficorella C, Iacobelli S, Natoli C; Consorzio Interuniversitario Nazionale per la Bio-Oncologia (CINBO). Meta-analysis of phase III trials of docetaxel alone or in combination with chemotherapy in metastatic breast cancer. J Cancer Res Clin Oncol. 2012 Feb;138(2):221-9.

31 Pallis AG, Boukovinas I, Ardavanis A, Varthalitis I, Malamos N, Georgoulias V, et al. A multicenter randomized phase III trial of vinorelbine/gemcitabine doublet versus capecitabine monotherapy in anthracyclineand taxane-pretreated women with metastatic breast cancer. Ann Oncol. 2012 May;23(5): 1164-9.

32 Dear RF, McGeechan K, Jenkins MC, Barratt A, Tattersall MH, Wilcken N. Combination versus sequential single agent chemotherapy for metastatic breast cancer. Cochrane Database Syst Rev. 2013 Dec;(12):CD008792. 
33 Robson M, Im SA, Senkus E, Xu B, Domchek SM, Masuda N, et al. Olaparib for Metastatic Breast Cancer in Patients with a Germline BRCA Mutation. N Engl J Med. 2017 Aug; 377(6):523-33.

34 Robson ME, Tung N, Conte P, Im SA, Senkus $\mathrm{E}, \mathrm{Xu} \mathrm{B}$, et al. OlympiAD final overall survival and tolerability results: olaparib versus chemotherapy treatment of physician's choice in patients with a germline BRCA mutation and HER2-negative metastatic breast cancer. Ann Oncol. 2019 Apr;30(4):558-66.

35 Robson M, Ruddy KJ, Im SA, Senkus E, Xu B, Domchek SM, et al. Patient-reported outcomes in patients with a germline BRCA mutation and HER2-negative metastatic breast cancer receiving olaparib versus chemotherapy in the OlympiAD trial. Eur J Cancer. 2019 Oct; $120: 20-30$.

36 Litton JK, Rugo HS, Ettl J, Hurvitz SA, Gonçalves A, Lee KH, et al. Talazoparib in Patients with Advanced Breast Cancer and a Germline BRCA Mutation. N Engl J Med. 2018 Aug; 379(8):753-63.

37 Ettl J, Quek RG, Lee KH, Rugo HS, Hurvitz S, Gonçalves A, et al. Quality of life with talazoparib versus physician's choice of chemotherapy in patients with advanced breast cancer and germline BRCA1/2 mutation: patientreported outcomes from the EMBRACA phase III trial. Ann Oncol. 2018 Sep;29(9): 1939-47.

38 Turner NC, Telli ML, Rugo HS, Mailliez A, Ettl J, Grischke EM, et al.; ABRAZO Study Group. A Phase II Study of Talazoparib after Platinum or Cytotoxic Nonplatinum Regimens in Patients with Advanced Breast Cancer and Germline BRCA1/2 Mutations (ABRAZO). Clin Cancer Res. 2019 May 25(9):2717-24.

39 Hurvitz SA, Gonçalves A, Rugo HS, Lee KH, Fehrenbacher L, Mina LA, et al. Talazoparib in Patients with a Germline BRCA-Mutated Advanced Breast Cancer: Detailed Safety Analyses from the Phase III EMBRACA Trial. Oncologist. 2020 Mar;25(3):e439-50.

40 Sammons S, Kornblum NS, Blackwell KL. Fulvestrant-Based Combination Therapy for Second-Line Treatment of Hormone Receptor-Positive Advanced Breast Cancer. Target Oncol. 2019 Feb;14(1):1-12.

41 André F, Ciruelos E, Rubovszky G, Campone M, Loibl S, Rugo HS, et al.; SOLAR-1 Study Group. Alpelisib for PIK3CA-Mutated, Hormone Receptor-Positive Advanced Breast Cancer. N Engl J Med. 2019 May;380(20): 1929-40.

42 Cardoso F, Senkus E, Costa A, Papadopoulos E, Aapro M, André F, et al. 4th ESO-ESMO International Consensus Guidelines for Advanced Breast Cancer (ABC 4). Ann Oncol. 2018 Aug;29(8):1634-57.

43 Turner NC, Ro J, André F, Loi S, Verma S, Iwata $\mathrm{H}$, et al.; PALOMA3 Study Group. Palbociclib in Hormone-Receptor-Positive Advanced Breast Cancer. N Engl J Med. 2015 Jul; 373(3):209-19.

44 Turner NC, Slamon DJ, Ro J, Bondarenko I, Im SA, Masuda N, et al. Overall Survival with Palbociclib and Fulvestrant in Advanced Breast Cancer. N Engl J Med. 2018 Nov; 379(20):1926-36.
45 Loibl S, Turner NC, Ro J, Cristofanilli M, Iwata $\mathrm{H}$, Im SA, et al. Palbociclib Combined with Fulvestrant in Premenopausal Women with Advanced Breast Cancer and Prior Progression on Endocrine Therapy: PALOMA-3 Results. Oncologist. 2017 Sep;22(9): 1028-38.

46 Tripathy D, Im SA, Colleoni M, Franke F, Bardia A, Harbeck N, et al. Ribociclib plus endocrine therapy for premenopausal women with hormone-receptor-positive, advanced breast cancer (MONALEESA-7): a randomised phase 3 trial. Lancet Oncol. 2018 Jul; 19(7):904-15.

47 Im SA, Mukai H, Park IH, Masuda N, Shimizu C, Kim SB, et al. Palbociclib Plus Letrozole as First-Line Therapy in Postmenopausal Asian Women With Metastatic Breast Cancer: Results From the Phase III, Randomized PALOMA-2 Study. J Glob Oncol. 2019 May;5(5): $1-19$.

48 Sledge GW Jr, Toi M, Neven P, Sohn J, Inoue $\mathrm{K}$, Pivot X, et al. MONARCH 2: Abemaciclib in Combination With Fulvestrant in Women With HR+/HER2- Advanced Breast Cancer Who Had Progressed While Receiving Endocrine Therapy. J Clin Oncol. 2017 Sep;35(25): 2875-84.

49 Sledge GW Jr, Toi M, Neven P, Sohn J, Inoue $\mathrm{K}$, Pivot X, et al. The Effect of Abemaciclib Plus Fulvestrant on Overall Survival in Hormone Receptor-Positive, ERBB2-Negative Breast Cancer That Progressed on Endocrine Therapy-MONARCH 2: A Randomized Clinical Trial. JAMA Oncol. 2019 Sep;6(1):11624.

50 Finn RS, Crown JP, Lang I, Boer K, Bondarenko IM, Kulyk SO, et al. The cyclin-dependent kinase 4/6 inhibitor palbociclib in combination with letrozole versus letrozole alone as first-line treatment of oestrogen receptorpositive, HER2-negative, advanced breast cancer (PALOMA-1/TRIO-18): a randomised phase 2 study. Lancet Oncol. 2015 Jan;16(1):25-35.

51 Finn RS, Martin M, Rugo HS, Jones S, Im SA, Gelmon K, et al. Palbociclib and Letrozole in Advanced Breast Cancer. N Engl J Med. 2016 Nov;375(20):1925-36.

52 Im SA, Lu YS, Bardia A, Harbeck N, Colleoni M, Franke F, et al. Overall Survival with Ribociclib plus Endocrine Therapy in Breast Cancer. N Engl J Med. 2019 Jul;381(4):307-16.

53 Rugo HS, Finn RS, Diéras V, Ettl J, Lipatov O, Joy AA, et al. Palbociclib plus letrozole as first-line therapy in estrogen receptor-positive/human epidermal growth factor receptor 2-negative advanced breast cancer with extended follow-up. Breast Cancer Res Treat. 2019 Apr;174(3):719-29.

54 Hortobagyi GN, Stemmer SM, Burris HA, Yap YS, Sonke GS, Paluch-Shimon S, et al. Ribociclib as First-Line Therapy for HR-Positive, Advanced Breast Cancer. N Engl J Med. 2016 Nov;375(18):1738-48.

55 Yardley DA, Hart L, Favret A, Blau S, Diab S, Richards D, et al. Efficacy and Safety of Ribociclib With Letrozole in US Patients Enrolled in the MONALEESA-2 Study. Clin Breast Cancer. 2019 Aug;19(4):268-277.e1.

56 Goetz MP, Toi M, Campone M, Sohn J, Paluch-Shimon S, Huober J, et al. MON-
ARCH 3: Abemaciclib As Initial Therapy for Advanced Breast Cancer. J Clin Oncol. 2017 Nov;35(32):3638-46.

57 Johnston S, Martin M, Di Leo A, Im SA, Awada A, Forrester T, et al. MONARCH 3 final PFS: a randomized study of abemaciclib as initial therapy for advanced breast cancer. NPJ Breast Cancer. 2019 Jan;5(1):5.

58 Slamon DJ, Neven P, Chia S, Fasching PA, De Laurentiis M, Im SA, et al. Phase III Randomized Study of Ribociclib and Fulvestrant in Hormone Receptor-Positive, Human Epidermal Growth Factor Receptor 2-Negative Advanced Breast Cancer: MONALEESA-3. J Clin Oncol. 2018 Aug;36(24):246572 .

59 Slamon DJ, Neven P, Chia S, Fasching PA, De Laurentiis M, Im SA, et al. Overall Survival with Ribociclib plus Fulvestrant in Advanced Breast Cancer. N Engl J Med. 2020 Feb; 382(6):514-24.

60 Klijn JG, Blamey RW, Boccardo F, Tominaga T, Duchateau L, Sylvester R; Combined Hormone Agents Trialists' Group and the European Organization for Research and Treatment of Cancer. Combined tamoxifen and luteinizing hormone-releasing hormone (LHRH) agonist versus LHRH agonist alone in premenopausal advanced breast cancer: a meta-analysis of four randomized trials. J Clin Oncol. 2001 Jan;19(2):343-53.

61 Rugo HS, Rumble RB, Macrae E, Barton DL, Connolly HK, Dickler MN, et al. Endocrine Therapy for Hormone Receptor-Positive Metastatic Breast Cancer: American Society of Clinical Oncology Guideline. J Clin Oncol. 2016 Sep;34(25):3069-103.

62 Forward DP, Cheung KL, Jackson L, Robertson JF. Clinical and endocrine data for goserelin plus anastrozole as second-line endocrine therapy for premenopausal advanced breast cancer. Br J Cancer. 2004 Feb;90(3): 590-4.

63 Park IH, Ro J, Lee KS, Kim EA, Kwon Y, Nam $\mathrm{BH}$, et al. Phase II parallel group study showing comparable efficacy between premenopausal metastatic breast cancer patients treated with letrozole plus goserelin and postmenopausal patients treated with letrozole alone as first-line hormone therapy. J Clin Oncol. 2010 Jun;28(16):2705-11.

64 Carlson RW, Theriault R, Schurman CM, Rivera E, Chung CT, Phan SC, et al. Phase II trial of anastrozole plus goserelin in the treatment of hormone receptor-positive, metastatic carcinoma of the breast in premenopausal women. J Clin Oncol. 2010 Sep;28(25):391721.

65 Bartsch R, Bago-Horvath Z, Berghoff A, DeVries C, Pluschnig U, Dubsky $\mathrm{P}$, et al. Ovarian function suppression and fulvestrant as endocrine therapy in premenopausal women with metastatic breast cancer. Eur J Can cer. 2012 Sep;48(13):1932-8.

66 Bonneterre J, Thürlimann B, Robertson JF, Krzakowski M, Mauriac L, Koralewski P, et al. Anastrozole versus tamoxifen as first-line therapy for advanced breast cancer in 668 postmenopausal women: results of the Tamoxifen or Arimidex Randomized Group Efficacy and Tolerability study. J Clin Oncol. 2000 Nov; 18(22):3748-57. 
67 Bonneterre J, Buzdar A, Nabholtz JM, Robertson JF, Thürlimann B, von Euler M, et al.; Investigators Committee Members. Anastrozole is superior to tamoxifen as first-line therapy in hormone receptor positive advanced breast carcinoma. Cancer. 2001 Nov;92(9): 2247-58.

68 Thürlimann B, Hess D, Köberle D, Senn I, Ballabeni P, Pagani O, et al. Anastrozole ("Arimidex") versus tamoxifen as first-line therapy in postmenopausal women with advanced breast cancer: results of the doubleblind cross-over SAKK trial 21/95 - a substudy of the TARGET (Tamoxifen or "Arimidex" Randomized Group Efficacy and Tolerability) trial. Breast Cancer Res Treat. 2004 Jun;85(3):247-54.

69 Mouridsen H, Gershanovich M, Sun Y, PerezCarrion R, Boni C, Monnier A, et al. Phase III study of letrozole versus tamoxifen as firstline therapy of advanced breast cancer in postmenopausal women: analysis of survival and update of efficacy from the International Letrozole Breast Cancer Group. J Clin Oncol. 2003 Jun;21(11):2101-9.

70 Paridaens R, Dirix L, Lohrisch C, Beex L, Nooij M, Cameron D, et al.; European Organization for the Research and Treatment of Cancer (EORTC) - Investigational Drug Branch for Breast Cancer (IDBBC). Mature results of a randomized phase II multicenter study of exemestane versus tamoxifen as firstline hormone therapy for postmenopausal women with metastatic breast cancer. Ann Oncol. 2003 Sep;14(9):1391-8.

71 Gibson L, Lawrence D, Dawson C, Bliss J. Aromatase inhibitors for treatment of advanced breast cancer in postmenopausal women. Cochrane Database Syst Rev. 2009 Oct;(4):CD003370.

72 Osborne CK. Tamoxifen in the treatment of breast cancer. N Engl J Med. 1998 Nov; 339(22):1609-18.

73 Ellis MJ, Llombart-Cussac A, Feltl D, Dewar JA, Jasiówka M, Hewson N, et al. Fulvestrant $500 \mathrm{mg}$ Versus Anastrozole $1 \mathrm{mg}$ for the FirstLine Treatment of Advanced Breast Cancer: Overall Survival Analysis From the Phase II FIRST Study. J Clin Oncol. 2015 Nov;33(32): 3781-7.

74 Di Leo A, Jerusalem G, Petruzelka L, Torres R, Bondarenko IN, Khasanov R, et al. Final overall survival: fulvestrant $500 \mathrm{mg}$ vs $250 \mathrm{mg}$ in the randomized CONFIRM trial. J Natl Cancer Inst. 2014 Jan;106(1):djt337.

75 Robertson JF, Bondarenko IM, Trishkina E, Dvorkin M, Panasci L, Manikhas A, et al. Fulvestrant $500 \mathrm{mg}$ versus anastrozole $1 \mathrm{mg}$ for hormone receptor-positive advanced breast cancer (FALCON): an international, randomised, double-blind, phase 3 trial. Lancet. 2016 Dec;388(10063):2997-3005.

76 Swain SM, Baselga J, Kim SB, Ro J, Semiglazov V, Campone M, et al.; CLEOPATRA Study Group. Pertuzumab, trastuzumab, and docetaxel in HER2-positive metastatic breast cancer. N Engl J Med. 2015 Feb;372(8):72434.
77 Verma S, Miles D, Gianni L, Krop IE, Welslau M, Baselga J, et al.; EMILIA Study Group. Trastuzumab emtansine for HER2-positive advanced breast cancer. N Engl J Med. 2012 Nov;367(19):1783-91.

78 Krop IE, Lin NU, Blackwell K, Guardino E, Huober J, Lu M, et al. Trastuzumab emtansine (T-DM1) versus lapatinib plus capecitabine in patients with HER2-positive metastatic breast cancer and central nervous system metastases: a retrospective, exploratory analysis in EMILIA. Ann Oncol. 2015 Jan;26(1):1139.

79 Cameron D, Casey M, Press M, Lindquist D, Pienkowski T, Romieu CG, et al. A phase III randomized comparison of lapatinib plus capecitabine versus capecitabine alone in women with advanced breast cancer that has progressed on trastuzumab: updated efficacy and biomarker analyses. Breast Cancer Res Treat. 2008 Dec;112(3):533-43.

80 Geyer CE, Forster J, Lindquist D, Chan S, Romieu CG, Pienkowski T, et al. Lapatinib plus capecitabine for HER2-positive advanced breast cancer. N Engl J Med. 2006 Dec; 355(26):2733-43.

81 von Minckwitz G, Schwedler K, Schmidt M, Barinoff J, Mundhenke C, Cufer T, et al.; GBG 26/BIG 03-05 study group and participating investigators. Trastuzumab beyond progression: overall survival analysis of the GBG 26/ BIG 3-05 phase III study in HER2-positive breast cancer. Eur J Cancer. 2011 Oct;47(15): 2273-81.

82 Baselga J, Gelmon KA, Verma S, Wardley A, Conte P, Miles D, et al. Phase II trial of pertuzumab and trastuzumab in patients with human epidermal growth factor receptor 2-positive metastatic breast cancer that progressed during prior trastuzumab therapy. J Clin Oncol. 2010 Mar;28(7):1138-44.

83 Blackwell KL, Burstein HJ, Storniolo AM, Rugo H, Sledge G, Koehler M, et al. Randomized study of Lapatinib alone or in combination with trastuzumab in women with ErbB2positive, trastuzumab-refractory metastatic breast cancer. J Clin Oncol. 2010 Mar;28(7): 1124-30.

84 Blackwell KL, Burstein HJ, Storniolo AM, Rugo HS, Sledge G, Aktan G, et al. Overall survival benefit with lapatinib in combination with trastuzumab for patients with human epidermal growth factor receptor 2-positive metastatic breast cancer: final results from the EGF104900 Study. J Clin Oncol. 2012 Jul; 30(21):2585-92.

85 Hu XC, Zhang J, Xu BH, Cai L, Ragaz J, Wang $\mathrm{ZH}$, et al. Cisplatin plus gemcitabine versus paclitaxel plus gemcitabine as first-line therapy for metastatic triple-negative breast cancer (CBCSG006): a randomised, open-label, multicentre, phase 3 trial. Lancet Oncol. 2015 Apr;16(4):436-46
86 Miles DW, Diéras V, Cortés J, Duenne AA, Yi J, O'Shaughnessy J. First-line bevacizumab in combination with chemotherapy for HER2negative metastatic breast cancer: pooled and subgroup analyses of data from 2447 patients. Ann Oncol. 2013 Nov;24(11):2773-80.

87 Miller KD, Chap LI, Holmes FA, Cobleigh MA, Marcom PK, Fehrenbacher L, et al. Randomized phase III trial of capecitabine compared with bevacizumab plus capecitabine in patients with previously treated metastatic breast cancer. J Clin Oncol. 2005 Feb;23(4): 792-9.

88 Miller K, Wang M, Gralow J, Dickler M, Cobleigh M, Perez EA, et al. Paclitaxel plus bevacizumab versus paclitaxel alone for metastatic breast cancer. N Engl J Med. 2007 Dec; 357(26):2666-76.

89 Yardley DA, Coleman R, Conte P, Cortes J, Brufsky A, Shtivelband M, et al.; tnAcity investigators. nab-Paclitaxel plus carboplatin or gemcitabine versus gemcitabine plus carboplatin as first-line treatment of patients with triple-negative metastatic breast cancer: results from the tnAcity trial. Ann Oncol. 2018 Aug;29(8):1763-70.

90 Zielinski C, Láng I, Inbar M, Kahán Z, Greil $\mathrm{R}$, Beslija S, et al.; TURANDOT investigators. Bevacizumab plus paclitaxel versus bevacizumab plus capecitabine as first-line treatment for HER2-negative metastatic breast cancer (TURANDOT): primary endpoint results of a randomised, open-label, non-inferiority, phase 3 trial. Lancet Oncol. 2016 Sep; 17(9):1230-9.

91 Chen IC, Lin CH, Huang CS, Lien HC, Hsu C, Kuo WH, et al. Lack of efficacy to systemic chemotherapy for treatment of metaplastic carcinoma of the breast in the modern era. Breast Cancer Res Treat. 2011 Nov;130(1): 345-51.

92 Loibl S, O'Shaughnessy J, Untch M, Sikov WM, Rugo HS, McKee MD, et al. Addition of the PARP inhibitor veliparib plus carboplatin or carboplatin alone to standard neoadjuvant chemotherapy in triple-negative breast cancer (BrighTNess): a randomised, phase 3 trial. Lancet Oncol. 2018 Apr;19(4):497-509.

93 Tutt A, Tovey H, Cheang MC, Kernaghan S, Kilburn L, Gazinska P, et al. Carboplatin in BRCA1/2-mutated and triple-negative breast cancer BRCAness subgroups: the TNT Trial. Nat Med. 2018 May;24(5):628-37.

94 Schmid P, Adams S, Rugo HS, Schneeweiss A, Barrios $\mathrm{CH}$, Iwata $\mathrm{H}$, et al.; IMpassion 130 Trial Investigators. Atezolizumab and NabPaclitaxel in Advanced Triple-Negative Breast Cancer. N Engl J Med. 2018 Nov; 379(22):2108-21.

95 Schmid P, Rugo HS, Adams S, Schneeweiss A, Barrios $\mathrm{CH}$, Iwata $\mathrm{H}$, et al.; IMpassion130 Investigators. Atezolizumab plus nab-paclitaxel as first-line treatment for unresectable, locally advanced or metastatic triple-negative breast cancer (IMpassion130): updated efficacy results from a randomised, double-blind, placebo-controlled, phase 3 trial. Lancet Oncol. 2020 Jan;21(1):44-59. 